\title{
Pharmacokinetic-Pharmacodynamic relationship of NRTIs and its connection to viral escape: An example based on Zidovudine
}

\author{
Max von Kleist ${ }^{\mathrm{a}, \mathrm{b}, *}$ Wilhelm Huisinga ${ }^{\mathrm{a}}$

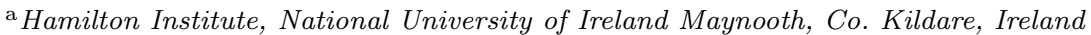 \\ ${ }^{\mathrm{b}}$ Freie Universität Berlin, Department of Mathematics and Computer Science
}

\begin{abstract}
In HIV disease, the mechanisms of drug-resistance are only poorly understood. Incomplete suppression of HIV by antiretroviral agents is suspected to be a main reason. The objective of this in silico study is to elucidate the pharmacokinetic origins of incomplete viral suppression, exemplified for zidovudine (AZT) as a representative of the key class of nucleoside reverse transcriptase inhibitors (NRTIs). AZT, like other NRTIs, exerts its main action through its intracellular triphoshate (AZT-TP) by competition with natural thymidine triphosphate. We developed a physiologically based pharmacokinetic (PBPK) model describing the intracellular pharmacokinetics of AZT anabolites and subsequently established the pharmacokinetic-pharmacodynamic relationship. The PBPK model has been validated against clinical data of different dosing schemes. We reduced the PBPK model to derive a simple threecompartment model for AZT and AZT-TP that can readily be used in population analysis of clinical trials. A novel machanistic, and for NRTIs generic effect model has been developed that incorporates the primary effect of AZT-TP and potential secondary effect of zidovudine monophosphate. The proposed models were used to analyze the efficacy and potential toxicity of different dosing schemes for AZT. Based on the mechanism of action of NRTIs, we found that drug heterogeneities due to temporal fluctuations can create a major window of unsuppressed viral replication. For AZT, this window was most pronounced for a $600 \mathrm{mg} / \mathrm{once}$ daily dosing scheme, in which insufficient viral suppression was observed for almost half the dosing period.
\end{abstract}

Key words: reverse transcription, intracellular phosphorylation, PBMC, HIV,CD4, pharmacodynamics

\section{Introduction}

Highly active antiretroviral therapy (HAART), in which three or more drugs are given in combination, has substantially improved the clinical management of human immunodeficiency virus (HIV) infection (Richman, 2001). However, the emergence of drug-resistant variants eventually leads to therapy failure in most patients (Struble et al., 2005; Tozzi et al., 2006). Up to now, the mechanisms of drug resistance are poorly understood. In (Kepler and Perelson, 1998), it is suggested that drug heterogeneity might create viral sanctuaries in which replication remains stable, allowing for resistance to develop and manifest (Kepler and Perelson, 1998; Pierson et al., 2000). Furthermore, as drugs are administered at discrete times so that the drug

\footnotetext{
* Corresponding Author

Email addresses: Max.VonKleist@nuim.ie (Max von Kleist), wilhelm.huisinga@nuim.ie (Wilhelm Huisinga).

$U R L$ : http://www.hamilton.ie/compphysiol (Max von Kleist).
}

concentration fluctuates temporally, they suspected that there may be a similar window of insufficient viral suppression due to temporal inhomogeneities. This hypothesis, although supported by many experimental findings (reviewed in (Schrager and D'Souza, 1998; Blankson et al., 2002)), has not been thoroughly analyzed in silico. In fact, only few mathematical models of HIV dynamics relate the degree of viral suppression to in vivo pharmacokinetics and pharmacodynamic parameters (Huang et al., 2003; Rosario et al., 2005; Dixit et al., 2004; Dixit and Perelson, 2004).

Most anti-HIV drugs act on intracellular targets (Owen and Khoo, 2004), and a high percentage of these drugs are substrates of some efflux transporters (Eilers et al., 2008; Janneh et al., 2005, 2007; Weiss et al., 2007; Hayashi et al., 2006). For the class of nucleoside reverse transcriptase inhibitors (NRTI), the current backbone of HAART, their pharmacological penetration into the target tissue/cells depends not only on the presence of transporters, but also on a cascade of intracellular activation (Painter et al., 2004). The abundance of the involved enzymes, and the affinity 
of the drug to the enzymes are important determinants of drug disposition.

For this class of pharmaceutics, the active intra-cellular moieties rather than the plasma markers are the important determinants relating to drug efficacy (Fletcher et al., 2000). Determining intracellular drug levels is usually costly, time-consuming and non-standard (Becher et al., 2002b,a; Compain et al., 2007). Understanding the intracellular pharmacokinetics of NRTIs, where the triphosphate moiety exerts the pharmacological action (Peter and Gambertoglio, 1998; Piliero, 2004; Painter et al., 2004), will therefore enhance our understanding of the evolutionary dynamics of HIV under NRTI treatment.

In this article, we focus on the thymidine analogue zidovudine (AZT) (Wilde and Langtry, 1993), as a representative of the class of NRTIs. In the case of AZT, the active triphosphate (AZT-TP) competes with the natural substrate deoxythymidine triphosphate (dTTP) for the reverse transcriptase of HIV. AZT-TP, once incorporated into the viral DNA chain, leads to chain termination and thereby inhibits virus proliferation (Langtry and Campoli-Richards, 1989).

Many studies focus on the pharmacokinetics of the prodrug, assuming a linear relationship between AZT and its active anabolite (e.g. (Panhard et al., 2007; Capparelli et al., 2003)). However, the relation between AZT and AZT-TP was shown to be non-linear (Wattanagoon et al., 2000; Stretcher et al., 1991; Anderson et al., 2003; Barry et al., 1996; Rodman et al., 1996; Aweeka et al., 2007).

Since NRTIs exert their pharmacological activity through competition with naturally occurring deoxynucleotide triphosphates, it has been shown for the class of NRTIs (Arts et al., 1996), and specifically for AZT (Fridland et al., 1990), that the nucleoside analogue triphosphate-to-deoxynucleotide triphosphate ratio is a major determinant for successful chain termination by NRTIs. In the case of AZT it has been shown that the main anabolite, zidovudine monophosphate (AZT-MP), causes depletion of dTTP levels (Furman et al., 1986; Fridland et al., 1990), which might be synergistic to the effect of AZT-TP on the reverse transcriptase of HIV.

So far there is no pharmacokinetic model which explicitly includes the phosphorylation cascade of AZT to AZTTP. The objective of the present study is to build a detailed PBPK model for zidovudine and its anabolites, based on in vitro and in vivo data. This allows us to study the origins of drug heterogeneity and the extent, to which temporal fluctuations can create windows of insufficient viral suppression - with the aim to help interpret outcomes of clinical trials (Shepp et al., 1997; Ruane et al., 2004). The proposed models, in particular the effect model, are applicable to investigate other NRTIs.

\section{Material and methods}

\subsection{Clinical trials on $A Z T$ and anabolites} pharmacokinetics.

Intracellular levels of AZT and its anabolites are very difficult to obtain and therefore only few clinical studies focus on the intracellular in vivo pharmacokinetics of AZT anabolites.

Since peripheral blood mononuclear cells (PBMCs) contain $\mathrm{CD} 4^{+}$-cells, the main target of HIV, they are currently used as a marker for target cell penetration of activated AZT moieties. The studies used for model validation are assessing AZT anabolite levels in PBMCs after various oral doses of zidovudine (Barry et al. (1996): 100mg; Aweeka et al. (2007); Barry et al. (1996): 300mg; Flynn et al. (2007): $600 \mathrm{mg}$ ) in HIV infected patients. The utilization of different doses allows us to identify concentration-dependent in vivo kinetics.

Tissue-to-plasma (or tissue-to-blood) partitioning coefficients are among the most important compound-specific input parameters in physiologically based pharmacokinetic modelling. For obvious reasons, these parameters are obtained from laboratory species, like rat, mouse, etc and subsequently extrapolated to assess human pharmacokinetics. We will utilize this strategy by considering the information about tissue partitioning from a study in mice (Chow et al., 1997). We chose this particular study, since it distinguishes between the different anabolites of AZT.

Table 1

Patient characteristics for the literature data that have been used to evaluate the pharmacokinetic model. The steady state indicates whether the patients in the respective study where in pharmacokinetic steady state prior to the start of the study ("Y" = Yes, "N" $=\mathrm{No}$ ). $\dagger$ healthy volunteers with a reference $\mathrm{CD}^{+}{ }^{+}$-count (Bisset et al., 2004). $\ddagger$ set to reference weight

\begin{tabular}{|l|l|l|l|}
\hline ref. & mean weight & mean $\mathrm{CD}^{+}$count & steady state \\
\hline Barry et al. $(1996)$ & $72.1[\mathrm{~kg}]$ & $221\left[10^{6}\right.$ cells $\left./ \mathrm{L}\right]$ & $\mathrm{Y}$ \\
Serra et al. (2008) & $60[\mathrm{~kg}]$ & $800 \dagger\left[10^{6}\right.$ cells $\left./ \mathrm{L}\right]$ & $\mathrm{N}$ \\
Aweeka et al. (2007) & $90.3[\mathrm{~kg}]$ & $503\left[10^{6}\right.$ cells $\left./ \mathrm{L}\right]$ & $\mathrm{Y}$ \\
Flynn et al. $(2007)$ & $70 \ddagger[\mathrm{kg}]$ & $550\left[10^{6}\right.$ cells $\left./ \mathrm{L}\right]$ & $\mathrm{Y}$ \\
\hline
\end{tabular}

\subsection{Detailed physiologically based pharmacokinetic model of zidovudine and its anabolites}

The physiologically based pharmacokinetic (PBPK) model structure of zidovudine and its mono-, di- and triphosphate anabolites is illustrated in Fig. 1A. The PBPK model consists of three anatomical compartments: blood, PBMCs, and 'rest of body'. PBMCs are included as an anatomical compartment due to their importance in HIV dynamics. They consist of different cell types, of which the largest fraction are T-cells (in healthy volunteers (Bisset et al., 2004)). 
AZT and AZT-MP are able to permeate cellular membranes, while the di- and triphosphate moiety are confined to the cellular spaces (Chow et al., 1997; Arnér et al., 1992). It has been observed that the cellular amounts of zidovudine diphosphate (AZT-DP) and AZT-TP are significantly smaller than the corresponding AZT and AZT-MP levels (approximately 1:100) (Wattanagoon et al., 2000; Barry et al., 1996; Rodman et al., 1996; Aweeka et al., 2007; Toyoshima et al., 1991; Furman et al., 1986; Arnér et al., 1992; Flynn et al., 2007). The levels of di- and triphosphates in the rest of the body insignificantly influence the kinetics of AZT and AZT-MP (Chow et al., 1997). Therefore, will model the di- and tri-phosphate species only in the effect compartment, i.e., the PBMCs. This assumption will subsequently allow us to derive a very simple, mechanismbased effect model.

The resulting system of differential equations including a detailed description of the kinetics is given in the supplementary material; corresponding parameter values are given in Tables 2 and 3.

Table 2

Estimated pharmacokinetic parameters.

\begin{tabular}{|l|l||l|l||l|l|}
\hline \multicolumn{5}{|c|}{ estimated pharmacokinetic parameters } \\
\hline param. & value & param. & value & param. & value \\
\hline$K_{\text {MP:AZT }}^{\mathrm{e}}$ & 6.14 & $v_{-3}[\mathrm{~mL} / \mathrm{h}]$ & 0.07 & $V_{\max }[\mathrm{pmol} / \mathrm{h}]$ & 135 \\
\hline
\end{tabular}

\subsubsection{Physiology}

The total body weights have been reported in the clinical trials (see Sec. 2.1). We assume a density of $1[\mathrm{~kg} / \mathrm{L}]$ to convert body weight to volume, and set $V_{\text {body }}$ equal to the mean body volume of the respective trial. The total blood volume $V_{\mathrm{b}}$ is set to be $5.4[\mathrm{~L}]$ (Brown et al., 1997). The volume of the 'rest of body' compartment $V_{\mathrm{r}}$ is given by $V_{\mathrm{r}}=V_{\text {body }}-V_{\mathrm{b}}-V_{\mathrm{e}}$, where $V_{\mathrm{e}}$ denotes the volume of the PBMCs. This has been estimated in the following way: The reference volume of a PBMC cells $V_{\mathrm{e}}$ has been identified with the volume of a T-cell, $V^{\mathrm{T}-\text { cell }}=140[\mathrm{fL}]$ (Begenisich et al., 2004). The total number of PBMCs is the sum of the $\mathrm{CD} 4^{+}$and $\mathrm{CD} 4^{-}$cells. The former are available for the different studies (Barry et al., 1996; Aweeka et al., 2007; Flynn et al., 2007; Marier et al., 2007), while the latter has been set to $800\left[10^{6}\right.$ cells/L] (based on an average total PBMC count of 1600 in healthy subjects, with a CD4fraction of $\sim 50 \%$ ) (Bisset et al., 2004).

The literature parameters are displayed in Table 3. Three parameters (the maximal phosphorylation velocity of AZTMP $V_{\max }=135[\mathrm{pmol} / \mathrm{h}]$, the velocity of AZT-DP dephosphorylation $v_{-3}=0.07[\mathrm{~mL} / \mathrm{h}]$ and the ratio of AZTMP-to-AZT in PBMCs $\left.K_{\mathrm{MP}: \mathrm{AZT}}^{\mathrm{e}}=6.14\right)$ were estimated from the in vivo data.

\subsubsection{Pharmacokinetic parameter estimation}

The parameter estimation was performed by the optimization routine lsqcurvefit in $\mathrm{MATLAB}^{\circledR}$, using a weighted least-squares criteria to estimate the goodness of fit, according to:

$\operatorname{err}=\sum_{i} \frac{\left|C\left(t_{i} ; p\right)-C_{\exp }\left(t_{i}\right)\right|^{2}}{C\left(t_{i} ; p\right)}$

where $p$ denotes the vector of parameters that have to be estimated. The values $t_{i}$ and $C_{\exp }\left(t_{i}\right)$ represent the experimental time points and the corresponding concentrations, respectively. The concentrations $C\left(t_{i} ; p\right)$ are determined as the numerical solution of the model equations with parameters $p$, evaluated at time points $t_{i}$. The relevant study and patient characteristics used for validation are given in Sec. 2.1.

\subsection{Reduced pharmacokinetic model suitable for population analysis}

PBPK models have generally too many parameters to allow for a reliable estimation of individual parameters of the entire model in the context of population analysis of clinical trials. In order to facilitate the use in this context, we will reduce the detailed $\mathrm{PBPK}$ model to a simpler compartment model. Analysis of the PBPK model yields the following insights: First, the concentrations of AZT and AZT-MP in the three anatomical compartments blood, 'rest of body', and PBMC are in quasi steady state. They can be related to each other and to the plasma concentration of AZT by some proportionality factor. Second, the concentrations of AZT-DP and AZT-TP in the PBMCs are in quasi steady state so that they can be related to each other by some proportionality factor. Third, AZT/AZT-MP and AZT-DP/$\mathrm{TP}$ are not linked by some constant factor, which is due to competitive and non-competitive inhibition of the thymidylate kinase by AZT-MP Lavie et al. (1997). Fourth, the dephosphorylation of AZT-DP has a negligible influence on the total AZT-MP concentration.

Hence, we propose a three compartment model. It comprises a central AZT compartment (volume $V_{1}$ and concentration $C_{1}$ ), a peripheral AZT compartment (volume $V_{2}$ and concentration $C_{2}$ ), and an AZT-TP effect compartment (volume $V 3$ and concentration $C_{3}$ ). The volume $V_{3}$ is related to the $\mathrm{CD} 4$ counts via $V_{3}=V^{\mathrm{T}-\text { cell }}\left(\mathrm{CD} 4^{+}\right.$count + CD4- count) $V_{\mathrm{b}}$. The inter-compartmental clearance between the central and peripheral compartment is denoted by $Q$; and dosing refers to the application of the drug (e.g., p.o. or i.v.). Then, the system of ODEs is given by

$V_{1} \frac{\mathrm{d}}{\mathrm{d} t} C_{1}=Q \cdot\left(C_{2}-C_{1}\right)-\mathrm{CL}_{1} \cdot C_{1}+\mathrm{dosing}$

$V_{2} \frac{\mathrm{d}}{\mathrm{d} t} C_{2}=Q \cdot\left(C_{1}-C_{2}\right)$

$V_{3} \frac{\mathrm{d}}{\mathrm{d} t} C_{3}=\frac{K_{\max } \cdot M_{1}}{K_{\mathrm{m}}^{\mathrm{MP}}\left(1+\frac{\mathrm{dTMP}}{K_{\mathrm{i}}^{\mathrm{dTMP}}}\right)+M_{1}\left(1+\frac{M_{1}}{K_{\mathrm{i}}^{\mathrm{MP}}}\right)}-v_{-3} C_{3}$

$M_{1}=K_{\mathrm{MP}: \mathrm{AZT}}^{\mathrm{e}: \mathrm{b}} \cdot C_{1}$. 


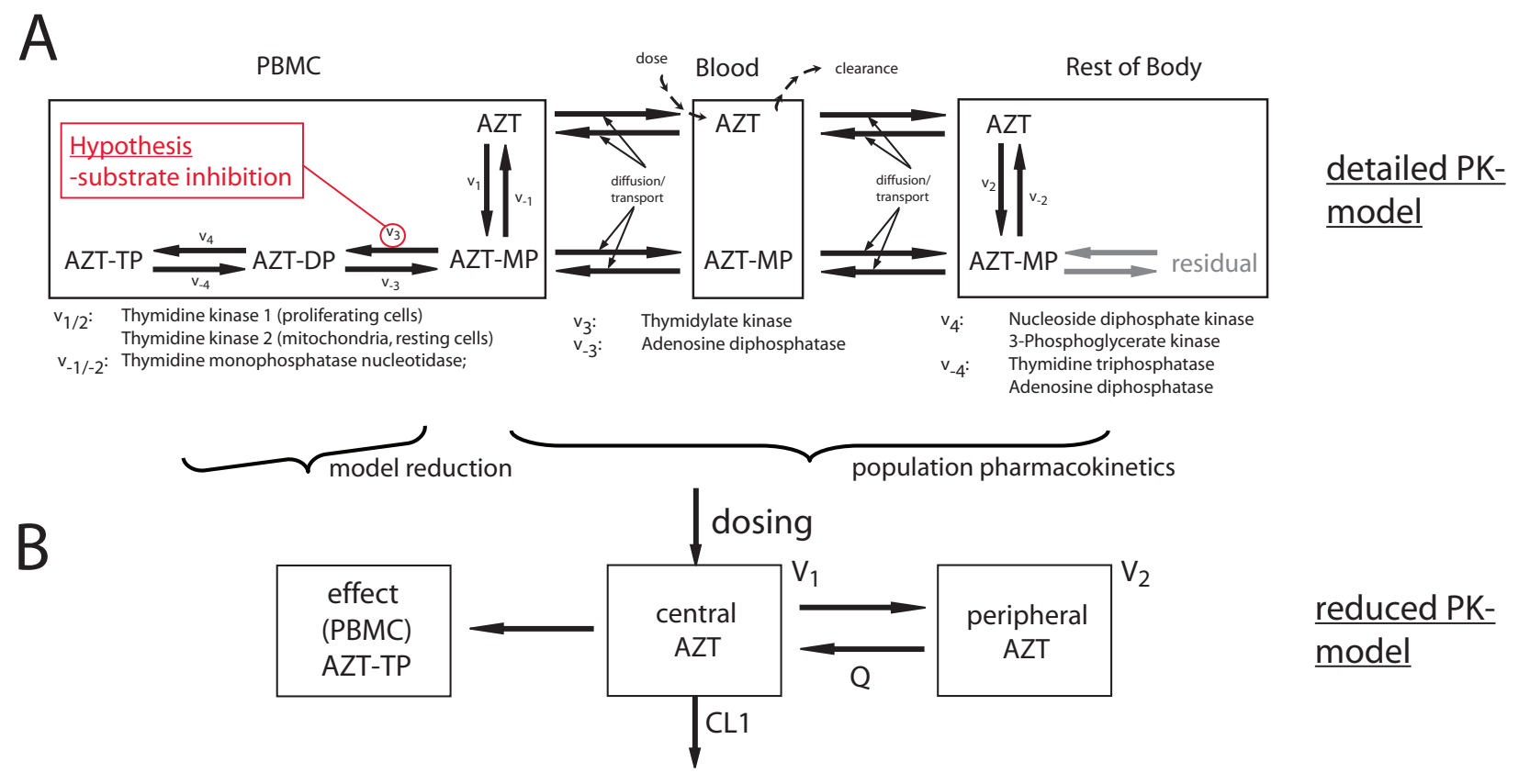

Fig. 1. A. Physiologically based compartment model for the PK of zidovudine and its anabolites. The corresponding system of ordinary differential equations is given in the supplementary material. B. Reduced PK model. The active intracellular AZT-TP is described as a function of the plasma AZT levels.

Table 3

Physiological, pharmacokinetic and pharmacodynamic literature parameters. For a description of the parameters see supplementary material.

\begin{tabular}{|c|c|c|c|c|c|}
\hline \multicolumn{6}{|c|}{ physiological } \\
\hline param. & value & ref. & param. & value & ref. \\
\hline$V^{\mathrm{b}}[\mathrm{L}]$ & 5.4 & (Brown et al., 1997) & $\mid \mathrm{CD}_{4}{ }^{-}\left[10^{6}\right.$ cells $\left./ \mathrm{L}\right]$ & 800 & (Bisset et al., 2004) \\
\hline$V^{\mathrm{T}-\text { cell }}[\mathrm{fL} /$ cell $]$ & 140 & (Begenisich et al., 2004) & |- & - & \\
\hline \multicolumn{6}{|c|}{ pharmacokinetic } \\
\hline $\mathrm{CL}[\mathrm{L} / \mathrm{min}]$ & 1.56 & (Acosta et al., 1996) & $K_{\mathrm{m}}^{\mathrm{MP}}[\mu \mathrm{M}]$ & 6 & (Lavie et al., 1997) \\
\hline $\mathrm{B}: \mathrm{P}$ & 0.86 & (Luzier and Morse, 1993) & $K_{\mathrm{MP}: \mathrm{AZT}}^{\mathrm{r}}$ & 0.071 & (Chow et al., 1997) \\
\hline $\mathrm{F}$ & 0.64 & (Wilde and Langtry, 1993) & $\| \mathrm{v}_{\text {fast }}[\mathrm{L} / \mathrm{min}]$ & $1 \cdot 10^{5}$ & - \\
\hline $\mathrm{fu}^{\mathrm{P}}$ & 0.75 & (Luzier and Morse, 1993) & $\| K_{\mathrm{DP}: \mathrm{TP}}$ & 1.1 & (Flynn et al., 2007) \\
\hline$K_{\mathrm{i}}^{\mathrm{MP}}[\mu \mathrm{M}]$ & 30 & (Lavie et al., 1997) & dTMP $[\mu \mathrm{M}]$ & 1.4 & (Traut, 1994) \\
\hline $\mathrm{k}_{A}\left[\min ^{-1}\right]$ & 0.022 & based on $t_{\max }$ (see text) & $K_{\mathrm{AZT}}^{\mathrm{up}: \mathrm{e}}$ & 1 & (Zimmerman et al., 1987) \\
\hline \multicolumn{6}{|c|}{ pharmacodynamic } \\
\hline$K_{\mathrm{m}}^{\mathrm{dTMP}}, K_{\mathrm{i}}^{\mathrm{dTMP}}[\mu \mathrm{M}]$ & 9 & (Lavie et al., 1997) & $\| K_{\mathrm{m}, \mathrm{TP}}^{\mathrm{RT}}[\mu \mathrm{M}]$ & 2.42 & (Cases-Gonzlez and Menndez-Arias, 2005) \\
\hline$K_{\mathrm{m}, \mathrm{dTTP}}^{\mathrm{RT}}[\mu \mathrm{M}]$ & 0.32 & (Cases-Gonzlez and Menndez-Arias, 2005) & $\| \mathrm{dTTP}(0)[\mu \mathrm{M}]$ & 4.1 & (Traut, 1994) \\
\hline
\end{tabular}

Above, $M_{1}$ denotes the AZT-MP concentration in the effect compartment, which is related to the concentration of $\mathrm{AZT}$ in the central compartment by the ratio $K_{\mathrm{MP}: \mathrm{AZT}}^{\mathrm{e}}=$ $K_{\mathrm{MP}: \mathrm{AZT}}^{\mathrm{e}} \cdot \mathrm{fu}^{\mathrm{p}} /\left(K_{\mathrm{AZT}}^{\mathrm{up}: \mathrm{e}} \cdot \mathrm{B}: \mathrm{P}\right)$. The parameter $K_{\max }$ denotes the apparent maximal conversion rate from AZTMP to AZT-TP (via AZT-DP), which is given by $K_{\max }=$ $V_{\max } /\left(1+K_{\mathrm{DP}: \mathrm{TP}}\right)$; and $K_{\mathrm{m}}^{\mathrm{MP}}$ denotes the corresponding Michaelis-Menten constant. The parameter $v_{-3}$ denotes the apparent dephosphorylation rate constant of AZT-TP, and dTMP denotes the deoxythymidine monophosphate concentration. Finally, $K_{\mathrm{i}}^{\mathrm{dTMP}}$ and $K_{\mathrm{i}}^{\mathrm{MP}}$ denote the corre- sponding non-competitive and competitive inhibition rate constants related to the conversion from the mono- to the di-phosphate.

Eq. (4) has been directly derived from the phophorylation and de-phophorylation reaction velocities in the detailed PBPK model (see supplementary material) under the above stated assumptions. It explicitly accounts for the competition with dTMP and the substrate inhibition by AZT-MP. We remark that the AZT plasma concentration acts only as an input into the AZT-TP effect compartment kinetics; there is no influence of $C_{3}$ on the kinetics of $C_{1}$ 
and $C_{2}$. This also implies that any model on AZT plasma kinetics (e.g., (Panhard et al., 2007; Gitterman et al., 1990; Mirochnick et al., 2007)) could be used to link it to the AZT-TP kinetics in eq. (4).

The compartment model (2)-(5) contains the 4 independent parameters: $V_{1}, V_{2}, Q$ and $\mathrm{CL}_{1}$, in addition to dosing. The remaining parameters are given in Table 3 and 2 , while CD4+ CD4- counts (entering $V_{3}$ ) have to be measured experimentally for each patient.

\subsection{Pharmacodynamics}

The target of ziduvodine and its anabolites is the process of reverse transcription. The effect is based on decreasing the likelihood of successful viral reverse transcription, i.e, DNA chain completion. AZT-TP competes with the natural substrate deoxythymidine triphosphate (dTTP) for binding to the reverse transcriptase (RT) and subsequent insertion into the DNA. AZT-TP insertion leads to DNA chain termination, thus inhibition of the reverse transcription process (Langtry and Campoli-Richards, 1989).

We aim at an effect model that accounts for the (i) competition between AZT-TP and ATTP for binding to the RT and subsequent insertion into the DNA chain, (ii) the reaction time for insertion, (iii) the fact that successful DNA chain completion requires $N$ consecutive insertions of dTTP, and (iv) the fact that successful insertion of AZTTP leads to a termination of chain prolongation and subsequent DNA chain degradation, such that the process of reverse transcription has to start again. Our starting point for modelling the effect of AZT-TP is to consider the likelihood of a single dTTP insertion, depending on competition with AZT-TP (see Fig. 2C).

If the discreteness of the reaction events and its sequence are important, the stochastic model of chemical reaction kinetics (Turner et al., 2004) is a much more appropriate description than the deterministic reaction rate model. In the stochastic setting, a bio-chemical reaction $R$ is specified in terms of a so-called propensity functions $a_{R}$ that is the probability that the reaction will take place in the next infinitesimal time interval. The propensity depends on the reaction constants and the abundance of the involved reactants. It is related to the next reaction time $\tau$ by $E(\tau)=$ $1 / a_{R}$, where $E(\tau)$ denotes the expected (mean) time to the next reaction event. In the case of two competing reactions $R_{1}$ and $R_{2}$ the expected time to the next reaction (either $R_{1}$ or $\left.R_{2}\right)$ is $E(\tau)=1 /\left(a_{R 1}+a_{R 2}\right)$. After this time, reaction $R_{1}$ will take place with probability $a_{R_{1}} /\left(a_{R 1}+a_{R 2}\right)$ and reaction $R_{2}$ will take place with probability $a_{R 2} /\left(a_{R 1}+a_{R 2}\right)$.

In the sequel we will use the abbreviations TP for AZTTP and MP for AZT-MP. The propensity $a_{+}(\mathrm{AZT})$ of prolongation of the DNA chain by a single dTTP in the presence of TP is given by
$a_{+}(\mathrm{AZT})=\frac{k_{\mathrm{cat}} \cdot \mathrm{RT} \cdot \mathrm{dTTP}}{K_{\mathrm{m}, \mathrm{dTTP}}^{\mathrm{RT}}\left(1+\frac{\mathrm{TP}}{K_{\mathrm{m}, \mathrm{TP}}^{\mathrm{RT}}}\right)+\mathrm{dTTP}}$,

where $k_{\text {cat }}[1 / \mathrm{s}]$ is the rate of insertion, and RT denotes the number of reverse transcriptases (Rao and Arkin, 2003). The parameters $K_{\mathrm{m} \text {,dTTP }}^{\mathrm{RT}}$ and $K_{\mathrm{m} \text {,TP }}^{\mathrm{RT}}$ denote the MichaelisMenten constants for insertion of dTTP and TP, respectively. Analogously, the propensity $a_{0}(\mathrm{AZT})$ of termination of the DNA chain by insertion of a single TP in the presence of dTTP is given by

$a_{0}(\mathrm{dTTP})=\frac{k_{\mathrm{cat}} \cdot \mathrm{RT} \cdot \mathrm{TP}}{K_{\mathrm{m}, \mathrm{TP}}^{\mathrm{RT}}\left(1+\frac{\mathrm{dTTP}}{K_{\mathrm{m}, \mathrm{dTTP}}^{\mathrm{RT}}}\right)+\mathrm{TP}}$.

Based on the above two propensities, we can compute the probability $q$ of dTTP insertion (under the condition that either AZT-TP or dTTP is inserted) according to

$q=\frac{a_{+}(\mathrm{AZT})}{a_{0}(\mathrm{dTTP})+a_{+}(\mathrm{AZT})}=\frac{1}{1+\frac{\mathrm{TP}}{\mathrm{dTTP}} \cdot \frac{K_{\mathrm{m}, \mathrm{dTTP}}^{\mathrm{RT}}}{K_{\mathrm{m}, \mathrm{TP}}^{\mathrm{RT}}}}$

Here, we used the fact that $k_{\text {cat }}$ for dTTP and AZT-TP incorporation are identical (Cases-Gonzlez and MenndezArias, 2005), so that $k_{\text {cat }}$ and RT cancel out and $q$ only depends on dTTP, AZT-TP, and the parameters $K_{\mathrm{m} \text {,dTTP }}^{\mathrm{RT}}$ and $K_{\mathrm{m}, \mathrm{TP}}^{\mathrm{RT}}$. After chain completion, the RT returns to the initial state with probability one (see Fig. 2C).

Successful completion of the viral DNA requires the incorporation of $N=2042$ or $N=3272$ thymidine bases for the DNA-DNA and RNA-DNA direction, respectively (GenBank accession no. AF033819). The effect of zidovudine and its anabolites is the deceleration of the reverse transcription process, i.e., the fraction $p$ of successful DNA chain completion in comparison to the untreated situation. Equivalently, the effect can be interpreted as the increase $1 / p$ in the mean time needed to successfully complete reverse transcription in comparison to the no-drug situation. Interpreting the effect model as a Markov chain allows us to determine the expected time to completion of the reverse transcription process in the presence of AZT $E_{\mathrm{AZT}}\left[\tau_{\mathrm{DNA}}\right]$ (see supplementary material) and the reduction $p$ of DNA chain completion as $p=E_{0}\left[\tau_{\mathrm{DNA}}\right] / E_{\mathrm{AZT}}\left[\tau_{\mathrm{DNA}}\right]$, or

$p=\frac{a_{+}(\mathrm{AZT})+a_{0}(\mathrm{dTTP})}{a_{+}(0)} \cdot N q^{N} \cdot \frac{1-q}{1-q^{N}}$.

The smaller $p$, the smaller the viral replication and therefore the more effective the drug. After a slight rearrangement of the above equation we obtain:

$p=\frac{a_{+}(\mathrm{AZT})}{a_{+}(0)} \cdot N q^{N-1} \frac{1-q}{1-q^{N}}$.

The overall effect $p$ can be further divided into a primary effect associated with AZT-TP, and a secondary effect associated with AZT-MP. The monophosphate has been shown 

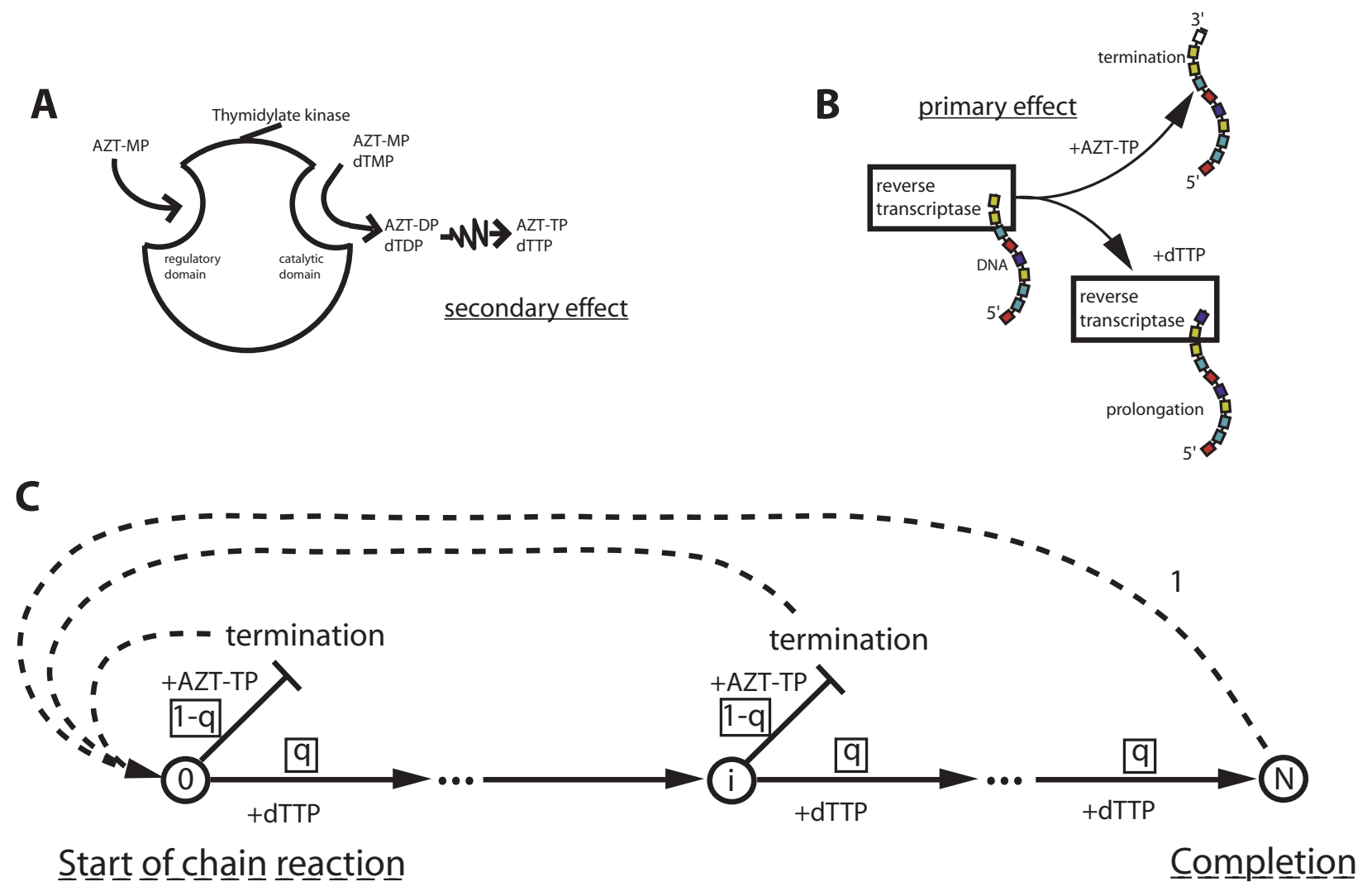

Fig. 2. AZT exerts its effect through AZT-TP and AZT-MP. Panel A: AZT-MP binds to a regulatory site of thymidylate kinase, reducing the catalytic efficacy of the enzyme. This can lead to depletion of dTTP levels, giving AZT-TP a competitive advantage over dTTP for the incorporation into the growing HIV-DNA. Panel B: AZT-TP competes with dTTP for incorporation into the growing DNA chain of HIV. If AZT-TP is incorporated, it leads to DNA chain termination. Incorporation of dTTP leads to DNA-chain prolongation. Panel C: Reverse transcriptase needs to incorporate $N=2042$ (DNA-DNA) or $N=3272$ (RNA-DNA) thymidine bases for successful completion of the viral DNA. The probability of successful thymidine incorporation is denoted by q. After chain termination, incomplete DNA is released and reverse transcription starts from the beginning.

to inhibit the thymidylate kinase competitively as well as non-competitively (Lavie et al., 1997). This enzyme is responsible for both the activation of AZT and deoxythymidine. The inhibition by AZT-MP causes depletion of dTTP levels (see Fig. 2A, and supplementary material).

\section{Results}

\subsection{Detailed PBPK model predicts experimental data of AZT and anabolites across different studies.}

We have validated the PBPK model with experimental data across different clinical studies, utilizing different dosing schemes. The simulated and the clinical data show good agreement (see Fig. 3 (left) and supplementary material). In Fig. 3 (right) we show a sample profile for an oral dose of $600 \mathrm{mg}$ AZT. The model simulations show a linear relation between plasma AZT and intra-cellular AZT-MP, a linear relation between AZT-DP and -TP, and a delayed relation between AZT-MP and AZT-DP. The inset illustrates the non-linear, saturable relation between AZT and AZT-TP due to substrate inhibition.

Part of the existing deviation between simulated and clinical data might be due to the large inter-individual variations in PBMC levels. In particular, it has been shown that (i) the variations in intracellular AZT-TP levels in PBMCs are mainly attributed to inter-individual variations of drug concentration in $\mathrm{CD}^{-}$and $\mathrm{CD} 3^{+} / \mathrm{CD} 4^{-}$cells in the PBMCs compartment (Anderson et al., 2007); and (ii) AZT-TP levels are lower in $\mathrm{CD}^{+}$cells than in the other cells contained in PBMCs. The relation, however, has not been fully resolved yet (Anderson et al., 2007). These two facts are likely to contribute to existing deviations.

\subsection{In silico analysis of toxicity and pharmacodynamics for different dosing schemes}

We used the PBPK model to analyze concentration time profiles of AZT-MP and AZT-TP for different dosing schemes in a $72[\mathrm{~kg}] \mathrm{HIV}$ positive human with $\mathrm{CD} 4^{+}$-count of 65 (fraction $\mathrm{CD}^{+}$in the $\mathrm{CD}^{+}$gate: 0.14 ): (a) $100 \mathrm{mg}$ six times a day (b) $100 \mathrm{mg}$ three times a day, (c) $300 \mathrm{mg}$ two times a day; and (d) $600 \mathrm{mg}$ once daily. The predicted 

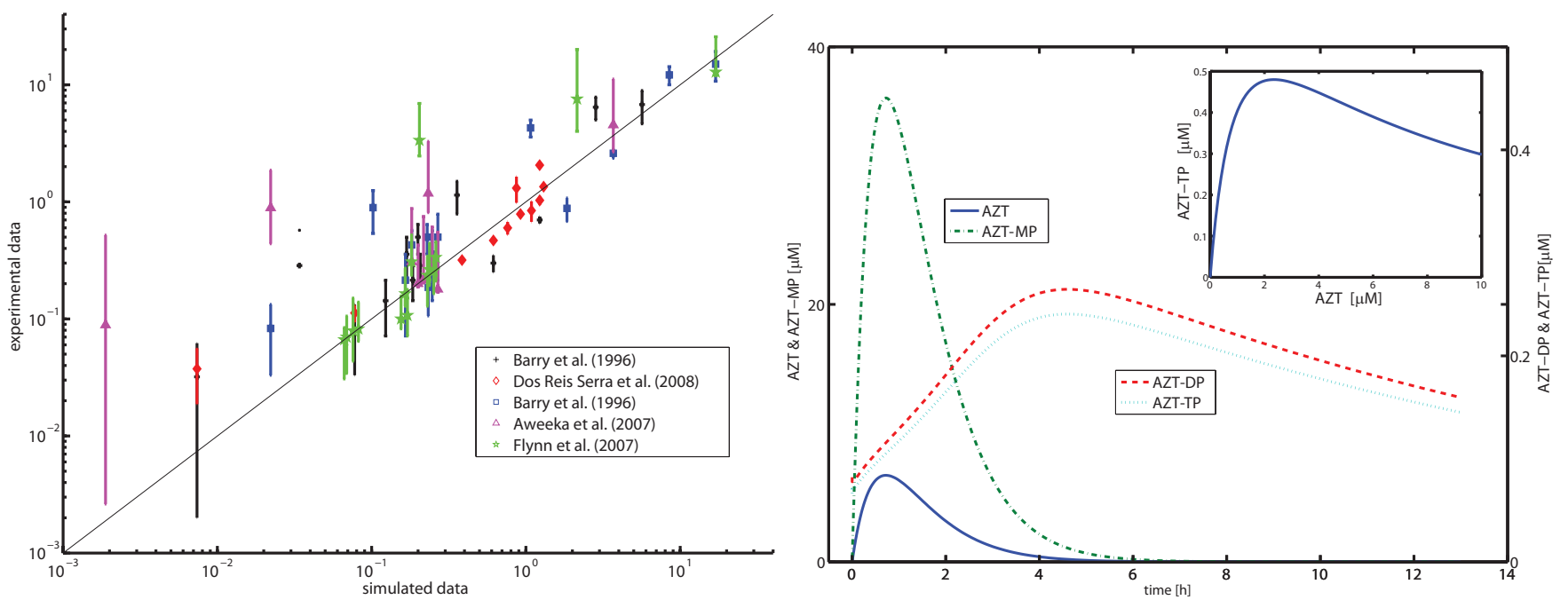

Fig. 3. Left panel: Simulated versus measured clinical data from Aweeka et al. (2007); Barry et al. (1996); Flynn et al. (2007); Serra et al. (2008). Clinical data comprises AZT (plasma) and AZT-MP, AZT-DP and AZT-TP in the PBMCs following oral doses of 100 , 300 and 600 [mg] zidovudine. Right panel: Sample profile for an oral dose of 600 [mg] zidovudine at steady state. The inset illustrates the saturable relation of AZT to AZT-TP (cf. eq. (4)).

concentration time profiles together with the experimental data from the different clinical studies are shown in the supplementary material. A summary related to exposure of AZT-MP and percentage residual RT activity is given in Table 4 . The $100 \mathrm{mg}$ six times daily scheme outperforms the other dosing schemes with regard to intracellular AZTTP levels, while the $600 \mathrm{mg}$ once daily dosing scheme is very inefficient compared to the other schemes. Regarding the exposure to AZT-MP, which is often connected to toxicity (Törnevik et al., 1995; Lynx et al., 2006; Susan-Resiga et al., 2007), the 100mg three times daily dosing scheme provides the smallest exposure to AZT-MP, while the exposure to AZT-MP is comparable for the other dosing schemes.

The inset in Fig. 3 (right) shows that the concentration of AZT-TP does not linearly increase with increasing AZT concentration. The AZT:AZT-TP graph shows the typical behavior of substrate inhibtion: increasing doses of AZT result in increasing concentrations of AZT-MP, which, on one hand, is converted into AZT-TP (via AZT-DP) and on the other hand inhibits its own conversion. Higher doses of AZT thus result in higher concentration of AZT-MP, but not AZT-TP.

\subsection{Reverse transcription under AZT treatment}

The percent of successful viral DNA reverse transcription under AZT treatment is shown in Figure 4 (left) for the different dosing schemes. It has been predicted based on eq. (9). The impact of low AZT-TP concentrations at the end of each dosing interval is most pronounced in the $600 \mathrm{mg}$ once daily dosing scheme. For the latter, the active drug concentration is insufficient for almost the entire second half of the dosing interval, leading to ineffective in- hibition of the reverse transcription process. This lack of effect coincides with the time at which levels of AZT-TP drop below approximately $0.05[\mu \mathrm{M}]$, and at which almost no dTDP depletion remains (see supplementary material). This implies that the chance of mutational viral escape is rising at the time before the next dosing in case of less frequent dosing. We evaluated the $\%$ of residual RT activity (relative to the absence of AZT) in Table 4 for a $24 \mathrm{~h}$ interval after reaching steady state (day $3-4$ ). It can be seen that for the $600 \mathrm{mg}$ dosing scheme insufficient inhibition (approx. $80 \%$ ) is reached in PBMCs.

Table 4

Exposure to AZT-MP and the efficacy of the treatment during $24 \mathrm{~h}$ after pharmacokinetic steady state (day 3-4). The efficacy is expressed in $\%$ of residual RT activity during the $24 \mathrm{~h}$ interval.

\begin{tabular}{|l|l|l|}
\hline dosing scheme & $\mathrm{AUC}_{0-24}(\mathrm{AZT}-\mathrm{MP})$ & $\%$ res. RT activity \\
\hline $100 \mathrm{mg}$ every 4h & $70.4[\mathrm{~h} \cdot \mu \mathrm{M}]$ & $3.6 \cdot 10^{-8}$ \\
$100 \mathrm{mg}$ every $8 \mathrm{~h}$ & $35.4[\mathrm{~h} \cdot \mu \mathrm{M}]$ & $5.9 \cdot 10^{-2}$ \\
$300 \mathrm{mg}$ every $12 \mathrm{~h}$ & $70.8[\mathrm{~h} \cdot \mu \mathrm{M}]$ & 0.26 \\
$600 \mathrm{mg}$ every 24h & $70.8[\mathrm{~h} \cdot \mu \mathrm{M}]$ & 18.9 \\
\hline
\end{tabular}

3.4. The effect of AZT-TP is highly sensitive to changes in the AZT-TP:dTTP ratio

The probability $q$ of a successful thymidine incorporation enters the effect model to the $(N-1)$ th power, where $N$ denotes the number of thymidine bases to be inserted into the growing DNA chain. It is a function of the AZTTP:dTTP ratio, see Fig. 4 (right). It can be seen that the effect of AZT-TP is highly sensitive to fluctuations in intracellular AZT-TP levels. For the reference ratio of the $K_{\mathrm{m}}$ values reported in Cases-Gonzlez and Menndez-Arias 

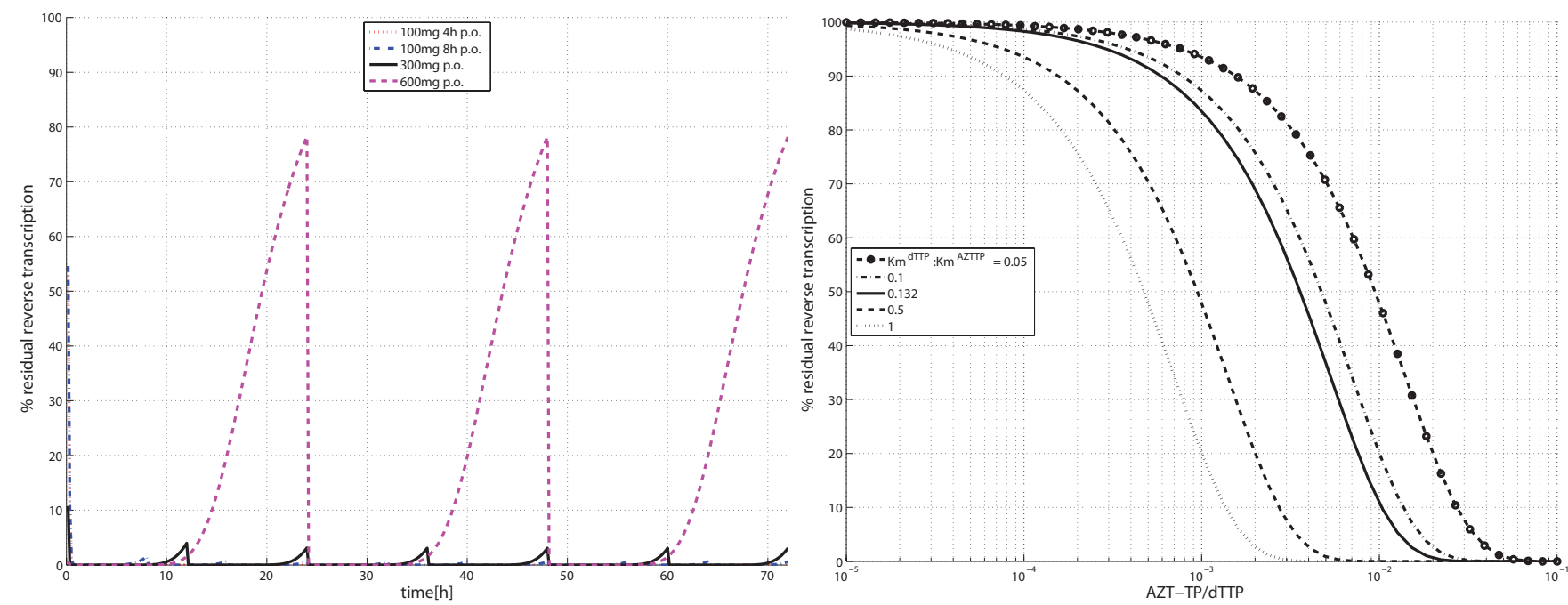

Fig. 4. Left panel: Residual virus DNA production for different dosing schemes after the initiation of AZT therapy. The curves show the \% residual reverse transcription (based on eq. (10)) after a once daily dose of 600 [mg] (dashed magenta line), a twice daily oral dose of 300 [mg] (solid black line), an oral dose of 100 [mg] every 8 hours (dash-dotted blue line) and an oral dose of 100 [mg] every 4 hours (dotted red line). Right panel: Influence of the dTTP:AZT-TP ratio on the suppression of reverse transcription for different $K_{\mathrm{m}, \mathrm{dTTP}}^{\mathrm{RT}} K_{\mathrm{m}, \mathrm{TP}}^{\mathrm{RT}} \mathrm{rtios}$ The solid line corresponds to the literature $K_{\mathrm{m}, \mathrm{dTTP}}^{\mathrm{RT}}: K_{\mathrm{m} \text {,TP }}^{\mathrm{RT}}$ ratio, while the other values are chosen to illustrate the impact of resistance mutation (rightmost lines) or hypersensitivity (leftmost lines) on \% residual reverse transcription.

(2005) - represented by the bold line in Fig. 4 (right) — we would expect the largest sensitivity for AZT-TP:dTTP ratios in the order of $10^{-3}-10^{-2}$. The pharmacokinetic fluctuations in intracellular AZT-TP:dTTP ratios were in the range: $0.08-0.16(100 \mathrm{mg} / 4 \mathrm{~h}) \quad 0.02-0.09(100 \mathrm{mg} / 8 \mathrm{~h})$, 0.016-0.2 (300mg/12h), 0.0014-0.25 (600mg/24h). Hence, the largest impact of drug fluctuations is expected for the $300 \mathrm{mg}$ and the $600 \mathrm{mg}$ dosing scheme, in accordance with Fig. 4 (left).

\subsection{The impact of resistance mutations}

HIV develops resistance against zidovudine by two distinct mechanisms: (i) lowering the affinity of AZT-TP to RT, and (ii) enhancing the ATP-dependent excision of incorporated AZT-TP (Clavel and Hance, 2004; Boyer et al., 2001; Ray et al., 2003). In terms of our mechanistic effect model, both processes can be accounted for by increasing $K_{\mathrm{m} \text {,TP }}^{\mathrm{RT}}$. This is illustrated in Fig. 4 (right), where the solid line corresponds to the reference ratio, while the other curves demonstrate the impact of resistance mutation (rightmost lines) or hypersensitivity (leftmost lines) on \% residual reverse transcription. As a net effect, changes in $K_{\mathrm{m} \text {,TP }}^{\mathrm{RT}}$ result in a shift of the most sensitive concentration range in terms of the AZT-TP:dTTP ratio.

\section{Discussion}

In this article, we propose a PBPK model of zidovudine and its anabolites. The PBPK model consists of a blood compartment, a 'rest of body' compartment and the
PBMCs as an effect compartment. Since zidovudine exerts its main action through its triphosphate species, which is produced from the parent compound through a cascade of intra-cellular phosphorylation steps, these steps are explicitly taken into account. The majority of model parameters were available from in vitro or in vivo experiments (see Table 3); the remaining three parameters were estimated from the in vivo data (see Table 2). The model was evaluated against experimental in vivo data of different dosing schemes (Barry et al. (1996): 100mg; Aweeka et al. (2007); Barry et al. (1996): 300mg; Flynn et al. (2007): 600mg) in HIV infected patients. While most studies only measure plasma levels of the pro-drug zidovudine, intra-cellular PBMC levels of the active zidovudine anabolites are rarely available. One aim of the current study is to use the available data in order to establish a link between the prodrug and its active species.

The model predictions were generally in good agreement with the experimental data (see Fig. 3 left). Despite their large variability, data (see supplementary material) and in silico predictions (see Fig. 3 right) clearly show (i) a linear relation between plasma AZT and intra-cellular AZTMP concentration; and (ii) a non-linear, time-delayed relation between intra-cellular AZT-MP and intra-cellular AZT-DP/TP levels. AZT and AZT-MP exhibit a shorter halflife and peak time than the higher anabolites (AZT-DP and AZT-TP) within the cells. All of these pharmacokinetic characteristics are very well reproduced by the model predictions.

The focus of the current study is to establish a general PK-PD relation rather than to optimize the fit to individual experimental data. Pharmacokinetic variability can be at- 
tributed to various sources: e.g., in PBMCs, it has been reported that the large variability in anabolite levels is mainly contributed to variability of AZT-TP levels in $\mathrm{CD}^{-}{ }^{-}$cells (within the PBMC compartment), which are not targeted by HIV (Anderson et al., 2007). Since CD4- counts are not available from the studies we did not attempt to include this factor into our model. We have parameterized the PBPK model on the basis of experimental in vivo data without further attempts to optimize these parameters.

In our PBPK modelling context, we were able to upgrade data on saturable AZT-MP phosphorylation from in vitro experiments (Lavie et al., 1997) to the in vivo situation. The pharmacokinetics of zidovudine and its anabolites are attributed to the intra-cellular phosphorylation/dephosphorylation cascade. The enzyme kinetics of thymidylate kinase and AZT-MP are able to explain the delayed and saturable intracellular AZT-TP concentrations. The longer halflife of the intracellular AZT-TP (in comparison to plasma AZT) has its origin in a slow de-phosphorylation of AZT-DP. No saturable steps were found in the phosphorylation/de-phosphorylation step between AZT and AZT-MP, as well as between AZT-DP and AZT-TP (see supplementary material). The in silico predictions show the same non-linear relation between the parent compound and the active species as the experimental data (Fig. 3 right, and supplementary material). Due to the saturable kinetics, the model predicts that there exists a maximal concentration of AZT-TP, beyond which it would not be possible to further increase the levels of intracellular AZT-TP with increasing doses of zidovudine.

In general, PBPK models do not aim at and are typically not suitable for estimation of individual parameters in clinical trials. This is the domain of population pharmacokinetics. In order to facilitate the transfer of our results into population analysis of clinical data, we derived a reduced compartment model. The saturable phosphorylation and slow de-phosphorylation events in the intracellular pharmacokinetics of AZT require to distinguish between plasma levels \& AZT anabolites with less than two phosphate groups (AZT, AZT-MP) and the higher anabolites (AZTDP, AZT-TP). Consequently, we propose a three compartment PK model of zidovudine in a central \& peripheral compartment and the active species zidovudine triphosphate in the PBMC effect compartment, see eqs. (2)-(4). The active AZT-TP concentration is linked to the prodrug concentration in the central compartment via eq. (4). This relation has been derived from the detailed PBPK model based on the assumptions that AZT and AZT-MP as well as AZTDP and AZT-TP are linearly correlated, and that the influence of dephosphorylation of AZT-DP on AZT-MP levels can be neglected due to a 100:1 ratio of AZT-DP:AZT-MP levels. Although we proposed a two compartment model for AZT, any compartment model of AZT could be used to link central AZT levels to AZT-TP levels in the effect compartment using the derived relation (4).

We have provided a quantitative assessment of the effect of pharmacokinetic profiles of AZT-MP and AZT-TP on suppression of reverse transcription. We used the proposed PBPK- and effect model to analyze four different dosing schemes in silico: $100 \mathrm{mg}$ every 4 hours, $100 \mathrm{mg}$ every 8 hours, $300 \mathrm{mg}$ every 12 hours and $600 \mathrm{mg}$ every 24 hours. From our simulations, we conclude that the 100mg (every 8 hours) dosing scheme has the best properties regarding (maximal) efficacy and (minimal) exposure to AZT-MP (see Table 4), when taking the kinetics in PBMCs as a reference for other target cells. In the case of the $600 \mathrm{mg}$ once daily dosing scheme, incomplete suppression can be seen in the time before the next dosing (Fig. 4, left). This apparent lack of efficacy could explain the observed weaker viral suppression for this dosing scheme in comparison with the 300mg twice daily scheme (Ruane et al., 2004). It is suspected to leave enough opportunities for viral escape in PBMCs. The other dosing schemes provide very good suppression of reverse transcription in PBMCs. When comparing the $300 \mathrm{mg}$ twice daily with the $100 \mathrm{mg}$ every 4 hours dosing scheme, similar exposure to AZT-MP is found and potent suppression of viral RT in both cases is observed (Table 4). The results are in agreement with clinical trials (Shepp et al., 1997), in which similar antiviral effects for both dosing schemes were observed. Also, the associated toxicity of both dosing strategies was comparable (Shepp et al., 1997).

AZT-TP levels in $\mathrm{CD}^{+}$cells are sufficiently lower than AZT-TP levels in other cells of the PBMC compartment (Anderson et al., 2003, 2007). The exact relation has not fully been resolved yet, however in (Anderson et al., 2007), concentrations of AZT-TP in $\mathrm{CD}^{+}$cells were related to the concentrations of AZT-TP in $\mathrm{CD} 4^{+}$depleted PBMC. For the analyzed extent of $\mathrm{CD} 4^{+}$depletion $\left(14 \% \mathrm{CD} 4^{+}\right.$ cells in the $\mathrm{CD}^{+}$gate) Anderson et al. (2007) found that the levels in purified $\mathrm{CD} 4^{+}$cells are approximately $25 \%$ of those in PBMCs. We might utilize this conversion factor to predict the levels of AZT-TP in $\mathrm{CD}^{+}$cells based on AZT-TP concentration in PBMCs. An analysis of the efficacy based on this assumption is presented in Table 5 .

\section{Table 5}

Efficacy expressed in \% of residual RT activity during the whole interval if the AZT-TP concentrations in $\mathrm{CD}^{+}$cells are $25 \%$ of those in PBMCs, as suggested by Anderson et al. (2007).

\begin{tabular}{|l|l|l|l|l|}
\hline dosing scheme $[\mathrm{mg}]$ & $100(/ 4 \mathrm{~h})$ & $100(/ 8 \mathrm{~h})$ & $300(/ 12 \mathrm{~h})$ & $600(/ 24 \mathrm{~h})$ \\
\hline$\%$ res. RT activity & 0.3 & 10 & 12 & 42 \\
\hline
\end{tabular}

We infer that all dosing schemes, except for the $100 \mathrm{mg}$ (every $4 \mathrm{~h}$ ) would insufficiently suppress viral replication in $\mathrm{CD}^{+}{ }^{+}$cells. However, this assumption remains speculative until further data is available.

We propose a novel effect model to predict the impact of zidovudine and its anabolites on the reverse transcrip- 
tion process. Our pharmacodynamic model considers the competitive mode of RT binding and the resultant chain termination mechanistically rather than empirically, utilizing experimental data from single nucleotide extension assays (Cases-Gonzlez and Menndez-Arias, 2005). The effect is described by the deceleration of successful viral DNA chain completion in the presence of zidovudine compared to the situation without drug treatment. The two potential mechanisms, by which zidovudine acts, can be analyzed separately. The primary effect is attributed to the insertion of AZT-TP into the growing DNA chain. Once inserted, the reverse transcription process is stopped, resulting in a degradation of the uncompleted DNA chain. As a net result this process increases the time to successful completion of the DNA chain. It has been shown in (Arts et al., 1996; Gao et al., 1999) that the AZT-TP:dTTP ratio is a major determinant of antiviral efficacy. Based on our proposed effect model, we can give a mechanistic justification of this determinant. The parameter with most influence on the overall effect is the probability of successful dTTP incorporation $q$. The relation between q, AZT-TP, dTTP and the $K_{\mathrm{m}}$ values is described by the very simple relation (8). It states that the larger the quotient AZT-TP:dTTP, the smaller $q$, as observed experimentally (Arts et al., 1996; Gao et al., 1999). The second factor involved in eq. (8) is the ratio $K_{\mathrm{m} \text {,dTP }}^{\mathrm{RT}}: K_{\mathrm{m} \text {,TP }}^{\mathrm{RT}}$. Mechanistically, AZT-TP powerfully inhibits reverse transcription due to the potentiation of a low probability of incorporation by a large number of opportunities for incorporation (Lavie et al., 1997). Therefore, very small changes in the extent of incorporation $q$ can have a dramatic effect on the degree of inhibition. In the light of our effect model (cf. eq.(10)), the probability of successful thymidine incorporation enters the effect model to the $(N-1)$ th power, where $N$ denotes the number of thymidine bases that have to be inserted. Therefore, the effect through AZT-TP is very sensitive to (a) variations in the AZT-TP:dTTP ratio caused by depletion of dTTP pools, or (b) temporal fluctuations in the AZT-TP concentrations caused by the pharmacokinetics after oral dosing and (c) small modifications in the affinity of AZT-TP to RT, e.g. as a result of mutations in the RT. Because the effect of AZT-TP (and other NRTIs) is highly sensitive to fluctuations in the AZT-TP:dTTP ratio, we speculate that the heterogeneities in the AZT-TP (and most likely other NRTI) levels can create a major window of unsuppressed viral replication.

Resistance against AZT-TP was attributed to two distinct mechanisms (Clavel and Hance, 2004; Boyer et al., 2001; Ray et al., 2003): (i) excision of AZT-TP from the DNA chain, and (ii) decrease in affinity of RT to AZT-TP. Both processes can be incorporated into our effect model by increasing $K_{\mathrm{m}}$. The predicted impact of resistance on the overall effect is shown in Fig. 4 (right) for multiple $K_{\mathrm{m}}$ ratios as a function of the AZT-TP:dTTP ratio.

The secondary effect of zidovudine is due to a potential depletion of the natural nucleotide dTTP by AZT-MP. In the absence of AZT-TP, this depletion has a minor influence on the deceleration of RT activity, while in the presence of AZT-TP, the dTTP:AZT-TP ratio is also modified, which enters the parameter $q$ in eq.(8) and thus has a large influence.

Our proposed effect model is not restricted to zidovudine but applicable to the broad class of NRTIs. The action of non-nocleoside reverse transcriptase inhibitors (NNRTIs) can also easily be incorporated into the effect model.

Most of the current models of HIV dynamics, e.g. (Perelson, 1999) and evolution, e.g. (Beerenwinkel et al., 2006) are based on the assumption of constant drug concentrations. Our results highlight the importance of drug pharmacokinetics, in the case of zidovudine on the delay of viral DNA chain completion. For many drugs, the impact of temporal fluctuations, attributed to the dosing schedule, on the emergence of drug resistant strains has not been investigated.

The majority of HIV-target cells does not reside within the blood compartment, but distributes widely in all tissues, organs and anatomical compartments (Koenig et al., 1986; Rappersberger et al., 1988; Stingl et al., 1990; Tschachler et al., 1987; McElrath et al., 1989; Meltzer et al., 1990), possibly serving as viral reservoirs (Stebbing et al., 2004). For AZT, and possibly other NRTIs, inefficient activation by intracellular enzymes constitutes a major bottleneck for their use (Gail Skowron and Ogden, 2006) and might lead to sub-inhibitory concentrations.

The potential impact of spatial drug heterogeneity on the emergence of drug resistance has been demonstrated in silico in (Kepler and Perelson, 1998). In this study we have demonstrated that temporal fluctuations may have a similar impact on the emergence of drug resistance.

\section{Acknowledgement.}

M. v. K. acknowledges financial support from the DFG Research Center MATHEON and the Hamilton Institute. Special thanks to Dr. Peter L. Anderson for help on the $\mathrm{CD} 4{ }^{+}$-PBMC correlation of AZT-TP and for providing data. Furthermore, the authors acknowledge fruitful discussions with Prof. Michael Mackey (McGill University).

\section{References}

Acosta, E. P., Page, L. M., Fletcher, C. V., 1996. Clinical pharmacokinetics of zidovudine. An update. Clin Pharmacokinet 30, 251-262.

Anderson, P. L., Kakuda, T. N., Kawle, S., Fletcher, C. V., 2003. Antiviral dynamics and sex differences of zidovu- 
dine and lamivudine triphosphate concentrations in HIVinfected individuals. AIDS 17, 2159-2168.

Anderson, P. L., Zheng, J.-H., King, T., Bushman, L. R., Predhomme, J., Meditz, A., Gerber, J., Fletcher, C. V., 2007. Concentrations of zidovudine- and lamivudinetriphosphate according to cell type in HIV-seronegative adults. AIDS 21, 1849-1854.

Arnér, E. S., Valentin, A., Eriksson, S., 1992. Thymidine and 3'-azido-3'-deoxythymidine metabolism in human peripheral blood lymphocytes and monocyte-derived macrophages. A study of both anabolic and catabolic pathways. J Biol Chem 267, 10968-10975.

Arts, E. J., Marois, J. P., Gu, Z., Grice, S. F. L., Wainberg, M. A., 1996. Effects of 3'-deoxynucleoside 5'triphosphate concentrations on chain termination by nucleoside analogs during human immunodeficiency virus type 1 reverse transcription of minus-strand strong-stop DNA. J Virol 70, 712-720.

Aweeka, F. T., Kang, M., Yu, J.-Y., Lizak, P., Alston, B., Chung, R. T., 5092s Study Team, A. I. D. S. C. T. G., 2007. Pharmacokinetic evaluation of the effects of ribavirin on zidovudine triphosphate formation: Actg 5092s study team. HIV Med 8, 288-294.

Barry, M. G., Khoo, S. H., Veal, G. J., Hoggard, P. G., Gibbons, S. E., Wilkins, E. G., Williams, O., Breckenridge, A. M., Back, D. J., 1996. The effect of zidovudine dose on the formation of intracellular phosphorylated metabolites. AIDS 10, 1361-1367.

Becher, F., Pruvost, A., Goujard, C., Guerreiro, C., Delfraissy, J.-F., Grassi, J., Benech, H., 2002a. Improved method for the simultaneous determination of $\mathrm{d} 4 \mathrm{~T}$, 3TC and ddl intracellular phosphorylated anabolites in human peripheral-blood mononuclear cells using highperformance liquid chromatography/tandem mass spectrometry. Rapid Commun Mass Spectrom 16, 555-565.

Becher, F., Schlemmer, D., Pruvost, A., Nevers, M.-C., Goujard, C., Jorajuria, S., Guerreiro, C., Brossette, T., Lebeau, L., Crminon, C., Grassi, J., Benech, H., 2002b. Development of a direct assay for measuring intracellular AZT triphosphate in humans peripheral blood mononuclear cells. Anal Chem 74, 4220-4227.

Beerenwinkel, N., Eriksson, N., Sturmfels, B., 2006. Evolution on distributive lattices. J Theor Biol 242, 409-420.

Begenisich, T., Nakamoto, T., Ovitt, C. E., Nehrke, K., Brugnara, C., Alper, S. L., Melvin, J. E., 2004. Physiological roles of the intermediate conductance, Ca2+activated potassium channel KCNN4. J Biol Chem 279, 47681-47687.

Bisset, L. R., Lung, T. L., Kaelin, M., Ludwig, E., Dubs, R. W., 2004. Reference values for peripheral blood lymphocyte phenotypes applicable to the healthy adult population in switzerland. Eur J Haematol 72, 203-212.

Blankson, J. N., Persaud, D., Siliciano, R. F., 2002. The challenge of viral reservoirs in HIV-1 infection. Annu Rev Med 53, 557-593.
Boyer, P. L., Sarafianos, S. G., Arnold, E., Hughes, S. H., 2001. Selective excision of AZTMP by drug-resistant human immunodeficiency virus reverse transcriptase. J Virol 75, 4832-4842.

Brown, R. P., Delp, M. D., Lindstedt, S. L., Rhomberg, L. R., Beliles, R. P., 1997. Physiological parameter values for physiologically based pharmacokinetic models. Toxicol Ind Health 13, 407-484.

Capparelli, E. V., Englund, J. A., Connor, J. D., Spector, S. A., McKinney, R. E., Palumbo, P., Baker, C. J., 2003. Population pharmacokinetics and pharmacodynamics of zidovudine in HIV-infected infants and children. J Clin Pharmacol 43, 133-140.

Cases-Gonzlez, C. E., Menndez-Arias, L., 2005. Nucleotide specificity of HIV-1 reverse transcriptases with amino acid substitutions affecting Ala-114. Biochem J 387, 221229.

Chow, H. H., Li, P., Brookshier, G., Tang, Y., 1997. In vivo tissue disposition of 3'-azido-3'-deoxythymidine and its anabolites in control and retrovirus-infected mice. Drug Metab Dispos 25, 412-422.

Clavel, F., Hance, A. J., 2004. HIV drug resistance. N Engl J Med 350, 1023-1035.

Compain, S., Durand-Gasselin, L., Grassi, J., Benech, H., 2007. Improved method to quantify intracellular zidovudine mono- and triphosphate in peripheral blood mononuclear cells by liquid chromatography-tandem mass spectrometry. J Mass Spectrom 42, 389-404.

Dixit, N. M., Markowitz, M., Ho, D. D., Perelson, A. S., 2004. Estimates of intracellular delay and average drug efficacy from viral load data of HIV-infected individuals under antiretroviral therapy. Antivir Ther 9, 237-246.

Dixit, N. M., Perelson, A. S., 2004. Complex patterns of viral load decay under antiretroviral therapy: influence of pharmacokinetics and intracellular delay. J Theor Biol 226, 95-109.

Eilers, M., Roy, U., Mondal, D., 2008. Mrp (ABCC) transporters-mediated efflux of anti-HIV drugs, saquinavir and zidovudine, from human endothelial cells. Exp Biol Med (Maywood).

Fletcher, C. V., Kawle, S. P., Kakuda, T. N., Anderson, P. L., Weller, D., Bushman, L. R., Brundage, R. C., Remmel, R. P., 2000. Zidovudine triphosphate and lamivudine triphosphate concentration-response relationships in HIV-infected persons. AIDS 14, 2137-2144.

Flynn, P. M., Rodman, J., Lindsey, J. C., Robbins, B., Capparelli, E., Knapp, K. M., Rodriguez, J. F., McNamara, J., Serchuck, L., Heckman, B., Martinez, J., the PACTG P1012 Team, 2007. Intracellular pharmacokinetics of once versus twice daily zidovudine and lamivudine in adolescents. Antimicrob Agents Chemother 51, 3516-3522.

Fridland, A., Connelly, M. C., Ashmun, R., 1990. Relationship of deoxynucleotide changes to inhibition of DNA synthesis induced by the antiretroviral agent 3'-azido-3'- 
deoxythymidine and release of its monophosphate by human lymphoid cells (CCRF-CEM). Mol Pharmacol 37, 665-670.

Furman, P. A., Fyfe, J. A., Clair, M. H. S., Weinhold, K., Rideout, J. L., Freeman, G. A., Lehrman, S. N., Bolognesi, D. P., Broder, S., Mitsuya, H., 1986. Phosphorylation of 3'-azido-3'-deoxythymidine and selective interaction of the 5'-triphosphate with human immunodeficiency virus reverse transcriptase. Proc Natl Acad Sci U S A 83, 8333-8337.

Gail Skowron, M., Ogden, R. (Eds.), 2006. Reverse Transcriptase Inhibitors in HIV/AIDS Therapy. Humana Press, Totowa, New Jersey.

Gao, W. Y., Johns, D. G., Tanaka, M., Mitsuya, H., 1999. Suppression of replication of multidrug-resistant HIV type 1 variants by combinations of thymidylate synthase inhibitors with zidovudine or stavudine. Mol Pharmacol $55,535-540$.

Gitterman, S. R., Drusano, G. L., Egorin, M. J., Standiford, H. C., 1990. Population pharmacokinetics of zidovudine. the veterans administration cooperative studies group. Clin Pharmacol Ther 48, 161-167.

Hayashi, K., Pu, H., Andras, I. E., Eum, S. Y., Yamauchi, A., Hennig, B., Toborek, M., 2006. HIV-tat protein upregulates expression of multidrug resistance protein 1 in the blood-brain barrier. J Cereb Blood Flow Metab 26, 1052-1065.

Huang, Y., Rosenkranz, S. L., Wu, H., 2003. Modeling HIV dynamics and antiviral response with consideration of time-varying drug exposures, adherence and phenotypic sensitivity. Math Biosci 184, 165-186.

Janneh, O., Jones, E., Chandler, B., Owen, A., Khoo, S. H., 2007. Inhibition of P-glycoprotein and multidrug resistance-associated proteins modulates the intracellular concentration of lopinavir in cultured CD4 T cells and primary human lymphocytes. J Antimicrob Chemother 60, 987-993.

Janneh, O., Owen, A., Chandler, B., Hartkoorn, R. C., Anthony Hart, C., Bray, P. G., Ward, S. A., Back, D. J., Khoo, S. H., 2005. Modulation of the intracellular accumulation of saquinavir in peripheral blood mononuclear cells by inhibitors of MRP1, MRP2, P-gp and BCRP. AIDS 19, 2097-2102.

Kepler, T. B., Perelson, A. S., 1998. Drug concentration heterogeneity facilitates the evolution of drug resistance. Proc Natl Acad Sci U S A 95, 11514-11519.

Koenig, S., Gendelman, H. E., Orenstein, J. M., Canto, M. C. D., Pezeshkpour, G. H., Yungbluth, M., Janotta, F., Aksamit, A., Martin, M. A., Fauci, A. S., 1986. Detection of AIDS virus in macrophages in brain tissue from AIDS patients with encephalopathy. Science 233, 1089-1093.

Langtry, H. D., Campoli-Richards, D. M., 1989. Zidovudine. A review of its pharmacodynamic and pharmacokinetic properties, and therapeutic efficacy. Drugs 37, 408450 .
Lavie, A., Schlichting, I., Vetter, I. R., Konrad, M., Reinstein, J., Goody, R. S., 1997. The bottleneck in AZT activation. Nat Med 3, 922-924.

Luzier, A., Morse, G. D., 1993. Intravascular distribution of zidovudine: role of plasma proteins and whole blood components. Antiviral Res 21, 267-280.

Lynx, M. D., Bentley, A. T., McKee, E. E., 2006. 3'-azido3'-deoxythymidine (AZT) inhibits thymidine phosphorylation in isolated rat liver mitochondria: a possible mechanism of AZT hepatotoxicity. Biochem Pharmacol 71, 1342-1348.

Marier, J. F., Dimarco, M., Guilbaud, R., Dodard, C., Morelli, G., Tippabhotla, S. K., Singla, A. K., Thudi, N. R., Monif, T., 2007. Pharmacokinetics of lamivudine, zidovudine, and nevirapine administered as a fixed-dose combination formulation versus coadministration of the individual products. J Clin Pharmacol 47, 1381-1389.

McElrath, M. J., Pruett, J. E., Cohn, Z. A., 1989. Mononuclear phagocytes of blood and bone marrow: comparative roles as viral reservoirs in human immunodeficiency virus type 1 infections. Proc Natl Acad Sci U S A 86, 675-679.

Meltzer, M. S., Nakamura, M., Hansen, B. D., Turpin, J. A., Kalter, D. C., Gendelman, H. E., 1990. Macrophages as susceptible targets for HIV infection, persistent viral reservoirs in tissue, and key immunoregulatory cells that control levels of virus replication and extent of disease. AIDS Res Hum Retroviruses 6, 967-971.

Mirochnick, M., Rodman, J. H., Robbins, B. L., Fridland, A., Ganda, J., Hitti, J., Bardeguez, A., Rathore, M. H., Garcia, A. G., Cababasay, M., Samson, P., Mofenson, L., Bryson, Y. J., Dorenbaum, A., 2007. Pharmacokinetics of oral zidovudine administered during labour: a preliminary study. HIV Med 8, 451-456.

Owen, A., Khoo, S. H., 2004. Intracellular pharmacokinetics of antiretroviral agents. J HIV Ther 9, 97-101.

Painter, G. R., Almond, M. R., Mao, S., Liotta, D. C., 2004. Biochemical and mechanistic basis for the activity of nucleoside analogue inhibitors of HIV reverse transcriptase. Curr Top Med Chem 4, 1035-1044.

Panhard, X., Legrand, M., Taburet, A.-M., Diquet, B., Goujard, C., Mentré, F., the Cophar 1 ANRS 102 Study Group, 2007. Population pharmacokinetic analysisof lamivudine, stavudine and zidovudine in controlled HIV-infected patients on HAART. Eur J Clin Pharmacol.

Perelson, A. S., 1999. Mathematical analysis of HIV-1 dynamics in vivo. SIAM Review 41, 3-44.

Peter, K., Gambertoglio, J. G., 1998. Intracellular phosphorylation of zidovudine (ZDV) and other nucleoside reverse transcriptase inhibitors (RTI) used for human immunodeficiency virus (HIV) infection. Pharm Res 15, 819-825.

Pierson, T., McArthur, J., Siliciano, R. F., 2000. Reservoirs for HIV-1: mechanisms for viral persistence in the 
presence of antiviral immune responses and antiretroviral therapy. Annu Rev Immunol 18, 665-708.

Piliero, P. J., 2004. Pharmacokinetic properties of nucleoside/nucleotide reverse transcriptase inhibitors. J Acquir Immune Defic Syndr 37 Suppl 1, S2-S12.

Rao, C. V., Arkin, A. P., 2003. Stochastic chemical kinetics and the quasi-steady-state assumption: Application to the Gillespie algorithm. J. Chem. Phys. 118, 4999-5010.

Rappersberger, K., Gartner, S., Schenk, P., Stingl, G., Groh, V., Tschachler, E., Mann, D. L., Wolff, K., Konrad, K., Popovic, M., 1988. Langerhans' cells are an actual site of HIV-1 replication. Intervirology 29, 185-194.

Ray, A. S., Murakami, E., Basavapathruni, A., Vaccaro, J. A., Ulrich, D., Chu, C. K., Schinazi, R. F., Anderson, K. S., 2003. Probing the molecular mechanisms of AZT drug resistance mediated by HIV-1 reverse transcriptase using a transient kinetic analysis. Biochemistry 42, 88318841.

Richman, D. D., 2001. HIV chemotherapy. Nature 410, 9951001.

Rodman, J. H., Robbins, B., Flynn, P. M., Fridland, A., 1996. A systemic and cellular model for zidovudine plasma concentrations and intracellular phosphorylation in patients. J Infect Dis 174, 490-499.

Rosario, M. C., Jacqmin, P., Dorr, P., van der Ryst, E., Hitchcock, C., 2005. A pharmacokineticpharmacodynamic disease model to predict in vivo antiviral activity of maraviroc. Clin Pharmacol Ther 78, $508-519$.

Ruane, P. J., Richmond, G. J., DeJesus, E., Hill-Zabala, C. E., Danehower, S. C., Liao, Q., Johnson, J., Shaefer, M. S., Team, C. O. D. S., 2004. Pharmacodynamic effects of zidovudine $600 \mathrm{mg}$ once/day versus $300 \mathrm{mg}$ twice/day in therapy-nave patients infected with human immunodeficiency virus. Pharmacotherapy 24, 307-312.

Schrager, L. K., D'Souza, M. P., 1998. Cellular and anatomical reservoirs of HIV-1 in patients receiving potent antiretroviral combination therapy. JAMA 280, 67-71.

Serra, C. H. D. R., Koono, E. E. M., Kano, E. K., Schramm, S. G., Armando, Y. P., Porta, V., 2008. Bioequivalence and pharmacokinetics of two zidovudine formulations in healthy brazilian volunteers: An open-label, randomized, single-dose, two-way crossover study. Clin Ther 30, 902908.

Shepp, D. H., Ramirez-Ronda, C., Dall, L., Pollard, R. B., Murphy, R. L., Kessler, H., Sherer, R., Mertz, G., Perez, G., Gocke, D. J., Greenberg, S. B., Petersen, E., Frank, I., Moore, M. D., McKinnis, R., Rooney, J. F., 1997. A comparative trial of zidovudine administered every four versus every twelve hours for the treatment of advanced HIV disease. J Acquir Immune Defic Syndr Hum Retrovirol 15, 283-288.

Stebbing, J., Gazzard, B., Douek, D. C., 2004. Where does HIV live? N Engl J Med 350, 1872-1880.

Stingl, G., Rappersberger, K., Tschachler, E., Gartner, S.,
Groh, V., Mann, D. L., Wolff, K., Popovic, M., 1990. Langerhans cells in HIV-1 infection. J Am Acad Dermatol 22, 1210-1217.

Stretcher, B. N., Pesce, A. J., Murray, J. A., Hurtubise, P. E., Vine, W. H., Frame, P. T., 1991. Concentrations of phosphorylated zidovudine (ZDV) in patient leukocytes do not correlate with ZDV dose or plasma concentrations. Ther Drug Monit 13, 325-331.

Struble, K., Murray, J., Cheng, B., Gegeny, T., Miller, V., Gulick, R., 2005. Antiretroviral therapies for treatmentexperienced patients: current status and research challenges. AIDS 19, 747-756.

Susan-Resiga, D., Bentley, A. T., Lynx, M. D., LaClair, D. D., McKee, E. E., 2007. Zidovudine inhibits thymidine phosphorylation in the isolated perfused rat heart. Antimicrob Agents Chemother 51, 1142-1149.

Törnevik, Y., Ullman, B., Balzarini, J., Wahren, B., Eriksson, S., 1995. Cytotoxicity of 3'-azido-3'-deoxythymidine correlates with 3'-azidothymidine-5'-monophosphate (AZTMP) levels, whereas anti-human immunodeficiency virus (HIV) activity correlates with 3'-azidothymidine5'-triphosphate (AZTTP) levels in cultured cem Tlymphoblastoid cells. Biochem Pharmacol 49, 829-837.

Toyoshima, T., Kimura, S., Muramatsu, S., Takahagi, H., Shimada, K., 1991. A sensitive nonisotopic method for the determination of intracellular azidothymidine 5'mono-, 5'-di-, and 5'-triphosphate. Anal Biochem 196, $302-307$.

Tozzi, V., Zaccarelli, M., Bonfigli, S., Lorenzini, P., Liuzzi, G., Trotta, M. P., Forbici, F., Gori, C., Bertoli, A., Bellagamba, R., Narciso, P., Perno, C. F., Antinori, A., for Clinical Use of HIV Genotype Resistance Test, C. G., 2006. Drug-class-wide resistance to antiretrovirals in hivinfected patients failing therapy: prevalence, risk factors and virological outcome. Antivir Ther 11, 553-560.

Traut, T. W., 1994. Physiological concentrations of purines and pyrimidines. Mol Cell Biochem 140, 1-22.

Tschachler, E., Groh, V., Popovic, M., Mann, D. L., Konrad, K., Safai, B., Eron, L., diMarzo Veronese, F., Wolff, K., Stingl, G., 1987. Epidermal langerhans cells-a target for HTLV-III/LAV infection. J Invest Dermatol 88, 233-237.

Turner, T. E., Schnell, S., Burrage, K., 2004. Stochastic approaches for modelling in vivo reactions. Computational Biology and Chemistry 28, 165-178.

Wattanagoon, Y., Bangchang, K. N., Hoggard, P. G., Khoo, S. H., Gibbons, S. E., Phiboonbhanakit, D., Karbwang, J., Back, D. J., 2000. Pharmacokinetics of zidovudine phosphorylation in human immunodeficiency viruspositive thai patients and healthy volunteers. Antimicrob Agents Chemother 44, 1986-1989.

Weiss, J., Rose, J., Storch, C. H., Ketabi-Kiyanvash, N., Sauer, A., Haefeli, W. E., Efferth, T., 2007. Modulation of human BCRP (ABCG2) activity by anti-HIV drugs. J Antimicrob Chemother 59, 238-245. 
Wilde, M. I., Langtry, H. D., 1993. Zidovudine. An update of its pharmacodynamic and pharmacokinetic properties, and therapeutic efficacy. Drugs 46, 515-578.

Zimmerman, T. P., Mahony, W. B., Prus, K. L., 1987. 3'-azido-3'-deoxythymidine. An unusual nucleoside analogue that permeates the membrane of human erythrocytes and lymphocytes by nonfacilitated diffusion. J Biol Chem 262, 5748-5754. 